\title{
PENERAPAN ALGORITMA FISHER-YATES SHUFFLE PADA COMPUTER BASED TEST UJIAN SEKOLAH DI SMKN 1 PAYUNG
}

\author{
Rendy Rian Chrisna Putra ${ }^{1}$, Tri Sugihartono ${ }^{2}$ \\ ${ }^{1,2}$ Program Studi Teknik Informatika, STMIK Atma Luhur \\ ${ }^{1,2}$ Jalan Jendral Sudirman, Pangkalpinang \\ ${ }^{1}$ Email : rendyriancp@atmaluhur.ac.id, ${ }^{2}$ Email : trisugihartono@atmaluhur.ac.id
}

\begin{abstract}
ABSTRAK
Ujian sekolah bertujuan salah satunya untuk mengukur keberhasilan proses belajar mengajar, apakah siswa mampu untuk menerima materi yang diajarkan dan apakah guru mampu memberikan materi dengan baik dan benar. Pada era zaman teknologi saat ini, SMKN 1 Payung sudah menggunakan teknologi CBT (Computer Based Test) dalam pelaksanaan ujian sekolah, kelebihan dari penggunaan CBT ini adalah paperless, dan hasil ujian dapat dilihat langsung setelah mengerjakan ujian, kelemahannya adalah kemungkinan siswa melakukan kecurangan seperti mencontek masih bisa terjadi. Untuk mengatasi kelemahan tersebut, maka diterapkan sebuah algoritma pengacakan soal yaitu algoritma Fisher-Yates Shuffle. Dengan menggunakan algoritma Fisher-Yates Shuffle, urutan soal yang diterima setiap siswa pada saat melaksanakan ujian sekolah berbasis CBT ini akan berbeda, sehingga mengurangi indikasi siswa untuk mencontek. Pada hasil penelitian, dilakukan pengujian menggunakan blackbox testing untuk menguji apakah fungsionalitas perangkat lunak sudah berfungsi dengan baik. Hasil implementasi dan testing yang diterapkan membuktikan dengan penerapan algoritma pengacakan soal Fisher-Yates Shuffle dapat membantu mengatasi kelemahan pada test berbasis komputer (CBT) di SMKN 1 Payung.
\end{abstract}

\section{Kata Kunci: Fisher-Yates, Algoritma Pengacakan, Tes Berbasis Komputer}

\section{ABSTRACT}

The school exam aims to measure the success of the teaching and learning process, whether students are able to accept the material taught and whether the teacher is able to provide the material properly and correctly. In the era of the current technological era, SMKN 1 Payung already uses CBT (Computer Based Test) technology in the implementation of school examinations, the advantages of using CBT are paperless, and the results of the exam can be seen immediately after the exam, the disadvantage is the possibility of students cheating like cheating can still happen. To overcome this weakness, a problem randomization algorithm is applied, namely the Fisher-Yates Shuffle algorithm. By using the Fisher-Yates Shuffle algorithm, the sequence of questions received by each student while carrying out this CBT-based school exam will be different, thereby reducing the indication of students to cheat. In the results of the study, testing is done using blackbox testing to test whether the software functionality is functioning properly. The results of the implementation and testing that are applied prove that using of the Fisher-Yates Shuffle algorithm can help overcome the weaknesses in computer-based tests (CBT) in SMKN 1 Payung.

\section{Keywords: Fisher-Yates, Shuffle Algorithm, Computer Based Test}

\section{PENDAHULUAN}

Pendidikan merupakan bagian terpenting dalam berlangsungnya kehidupan suatu negara, pendidikan juga penting bagi semua orang, karena melalui pendidikan, seseorang dapat menerima pengetahuan, dan keterampilan.

Salah satu cara untuk menerima pendidikan adalah melalui sekolah, dan salah satu cara untuk mengetahui hasil pendidikan yang diberikan adalah melalui ujian sekolah. Ujian sekolah merupakan rutinitas yang dilakukan dengan tujuan untuk mengukur proses belajar mengajar, apakah siswa mampu untuk menerima materi yang diajarkan dan apakah guru mampu memberikan materi dengan baik dan benar.

Dengan memanfaatkan teknologi saat ini, pelaksanaan ujian secara konvensional dapat diganti menjadi terkomputerisasi yang disebut dengan tes berbasis komputer (computer based test). Tes berbasis komputer adalah tes yang memanfaatkan komputer sebagai media utama dalam pelaksanaan ujian. Perbedaan tes konvensional dengan tes berbasis komputer yaitu pada tes berbasis komputer tidak memerlukan kertas lagi untuk penyampaian soal dan penulisan lembar jawaban, dan pada tes berbasis komputer, hasil ujian dapat langsung ditampilkan ketika selesai. 
Kelemahan tes berbasis komputer dan tes konvensional adalah kemungkinan terjadinya kecurangan seperti mencontek masih bisa terjadi, karena penyampaian soal masih diberikan secara berurutan kepada setiap siswa. Untuk mengatasi kelemahan tersebut, dibutuhkan sebuah algoritma pengacakan soal ujian.

Algoritma pengacakan soal ujian selain menggunakan algoritma fisher-yates shuffle, masih banyak lagi nama-nama algoritma untuk pengacakan soal seperti algoritma linear congruential generator (LCG), algoritma linear congruent method (LCM), dan algoritma backtracking.

Algoritma pengacakan fisher-yates biasa juga dikenal dengan nama pengacakan knuth atau pengacakan fisher-yates-knuth memilik cara kerja seperti tampak pada gambar dibawah ini.

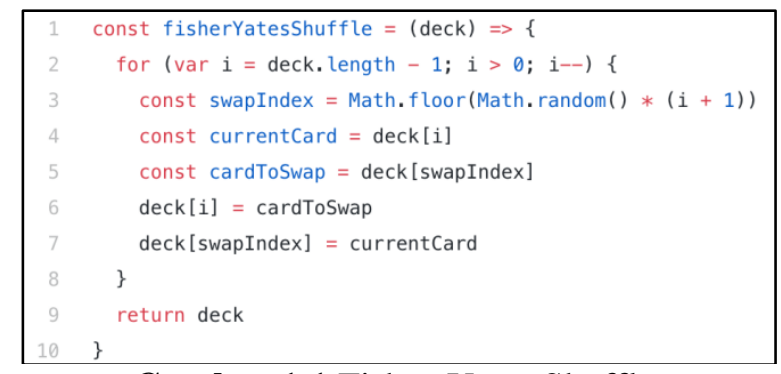

Gambar 1.1 Fisher-Yates Shuffle

Dari gambar diatas diilustrasikan pengocokan pada kartu, iterasi melalui setiap kartu, mencari semua posisi (index) yang belum dikocok, semua swap terjadi di tempat pada akhir array, dan begitu kartu "dikocok" ke tempatnya, kartu tidak dapat bergerak lagi. Ini membatasi hasil yang mungkin sama dengan jumlah permutasi yang mungkin dalam dek 4 kartu, jadi akan mulai dengan berpotensi menukar salah satu dari 4 kartu, kemudian saat kita bergerak melalui dek atau array, beralih dari 3 ke 2 untuk 1 kartu swappable yang tersisa (jadi $4 * 3 * 2 * 1)$ [1].

Dengan menerapkan algoritma fisheryates shuffle untuk mengacak soal ujian, sehingga setiap siswa tidak akan mendapatkan soal dengan urutan yang sama. Algoritma fisheryates shuffle dianggap oleh banyak orang sebagai metode untuk menghasilakn permutasi acak dari suatu set terbatas. Algoritma fisheryates shuffle yang pertama diusulkan pada tahun 1938 dan dikaji pada tahun 1948 dengan versi modern yang disajikan dalam sebuah varian [2].
Penelitian sebelumnya yang dilakukan Ade-Ibijola dan A. Olu dengan penelitiannya yang menerapkan algoritma fisher-yates shuffle pada permainan kartu virtual [3], penelitian yang dilakukan A. A. In'Amin, menerapkan algoritma fisher-yates shuffle untuk game edukasi dengan tujuan agar konten pada game lebih interaktif dan menarik [4], penelitian yang dilakukan R. Nugraha dkk, juga menerapkan algoritma fisheryates shuffle ini pada aplikasi untuk pengenalan jenis serangga [5], penelitian yang dilakukan I. Haditama dkk, menerapkan algoritma fisheryates shuffle untuk kuis tebak nada sunda berbasis android [6]. Dengan mempelajari algoritma fisher-yates shuffle pada penelitian sebelumnya yang diterapkan pada permainan dan kuis, maka penulis berinisiatif untuk menerapkan pada CBT Ujian Sekolah.

\section{METODOLOGI}

\subsection{Metode Pengumpulan Data}

Metode pengumpulan data yang digunakan dalam penelitian ini sebagai berikut:

1. Studi Pustaka

Melakukan studi literatur yang diambil dari berbagai referensi mulai dari buku, penelitian terdahulu yang sudah dilakukan, dan sumber valid dan terpercaya lainnya dari internet.

2. Wawancara

Melakukan tanya jawab dengan Ibu Asmi selaku guru di SMKN 1 Payung.

3. Observasi

Melakukan pengamatan ujian sekolah berlangsung di SMKN 1 Payung.

\subsection{Model Pengembangan Perangkat Lunak}

Model yang digunakan dalam penelitian ini adalah model waterfall [7], yang terbagi menjadi 4 tahapan, yaitu:

1. Analisis

Tahap awal yang dilakukan adalah merencanakan konsep dasar dari aplikasi. Pengumpulan kebutuhan perangkat lunak agar mudah dipahami. Pada tahapan ini, dilakukan pengumpulan data dan analisa sistem ujian test berbasis komputer pada SMKN 1 Payung.

2. Perancangan

Tahap perancangan merupakan proses lanjutan dari proses analisa dimana pada tahapan ini membuat rancangan tentang apa yang diperlukan seperti rancangan layar dan diagram aplikasi perangkat lunak. 


\section{Implementasi}

Tahap pelaksanaan atau penerapan dari perangkat lunak yang sebelumnya sudah dirancang dan dibangun.

4. Pengujian

Tahap akhir dimana perangkat lunak yang baru diimplementasikan diuji kemampuan dan fungsionalitasnya sehingga didapatkan kekurangan dan kelemahan perangkat lunak yang kemudian dapat dilakukan pengkajian ulang dan perbaikan, pada tahap pengujian ini menggunakan blackbox testing.

\subsection{Metode Pengembangan Perangkat Lunak}

Metode berorientasi objek digunakan sebagai metode dalam pengembangan sistem ini, metode berorientasi objek adalah metode yang meliputi rangkaian aktivitas analisi berorientasi objek, perancangan berorientasi objek, pemrograman berorientasi objek, dan pengujian berorientasi objek. Dengan menggunakan teknik yang menghasilkan produk yang sesuai dengan kriteria untuk setiap aktivitas yang dilakukan dengan menggunkan alat bantu untuk memodelkan (mendokumentasi) hasil dari setiap aktivitas [8].

\subsection{Tool Pengembangan Perangkat Lunak}

Tool pengembangan perangkat lunak yang digunakan adalah 4 diagram yang ada pada Unified Modeling Language (UML). Unified Modeling Language (UML) adalah salah satu standar bahasa yang banyak digunakan di dunia untuk menjelaskan apa yang dilakukan oleh sistem, membuat analisis dan desain alur Aplikasi, serta menggambarkan arsitektur dalam pemrograman berorientasi objek. UML merupakan bahasa visual untuk pemodelan dari komunikasi mengenai sebuah sistem dengan menggunakan diagram dan teks-teks pendukung untuk menggambarkan proses pembuatan aplikasi yang akan dibuat [9]. Keempat diagram tersebut yaitu:

1. Use Case Diagram

Pada diagram use case memberikan gambaran tentang interaksi yang terjadi antara aktor.

\section{Activity Diagram}

Pada diagram ini menjabarkan model fungsi-fungsi dalam aplikasi yang akan dibangun, dimana diagram ini nantinya akan memberikan gambaran mengenai aliran kendali antar objek dari aplikasi yang dibangun.

\section{Class Diagram}

Class diagram berfungsi untuk menampilkan kelas dan paket pada aplikasi yang sedang kita gunakan, jadi sebelum membangun sebuah aplikasi, kita harus merancang class diagram terlebih dahulu.

4. Sequence Diagram

Sequnce diagram atau yang biasa disebut dengan diagram urutan menjelaskan bagaimana suatu objek atau entitas di dalam perangkat lunak berinteraksi, simbol yang terdapat pada diagram urutan ini adalah actor, class, lifeline, dan line message.

\section{HASIL DAN PEMBAHASAN}

3.1 Use Case Diagram

Perancangan use case diagram yang diusulkan adalah sebagai berikut:

1. Use Case Admin

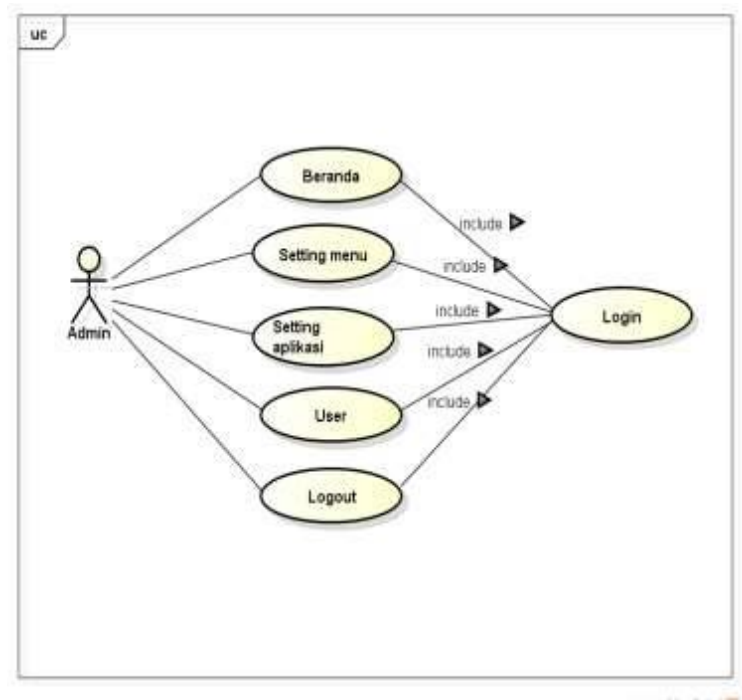

Gambar 3.1 Use Case Admin

2. Use Case Guru

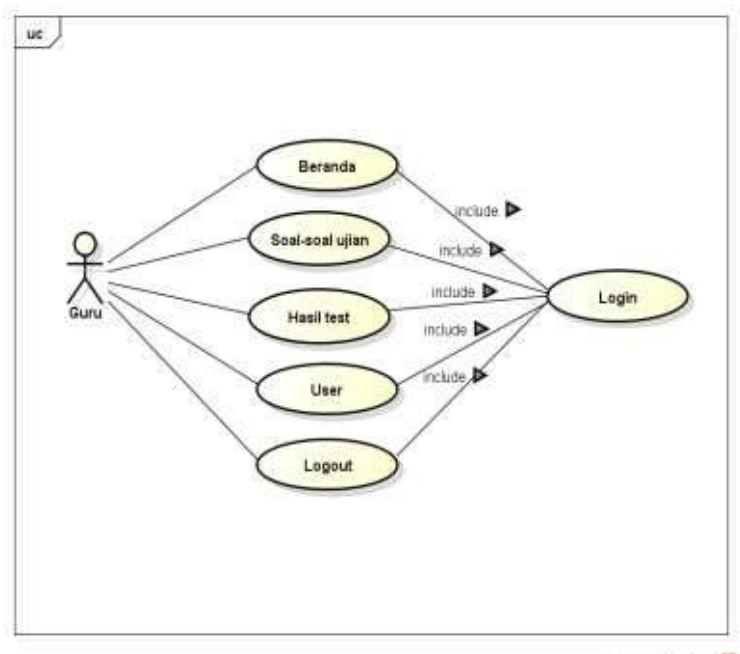

Gambar 3.2 Use Case Guru 
3. Use Case Siswa

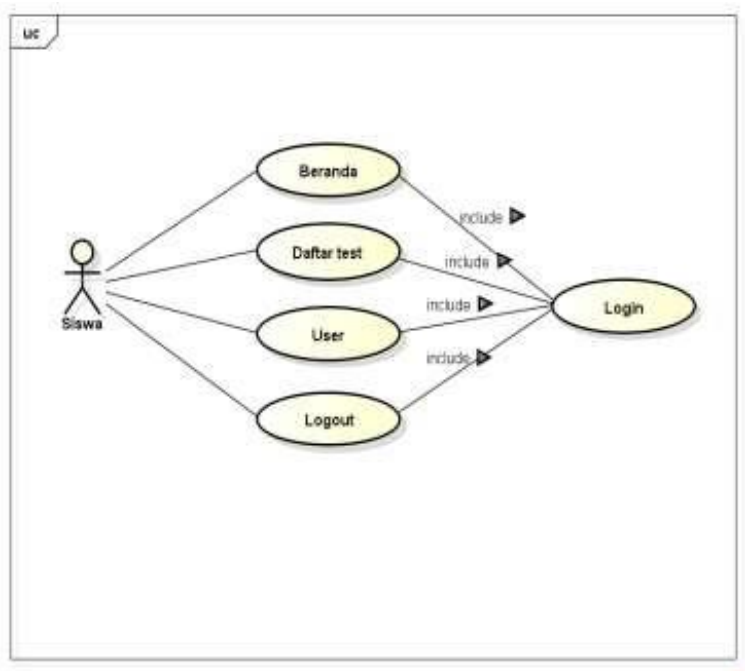

Gambar 3.3 Use Case Siswa

\subsection{Activity Diagram}

Berikut adalah Activity diagram yang mengacu pada setiap skenario Activity Diagram yang ada pada pengembangan aplikasi :

1. Activity Diagram manajemen soal

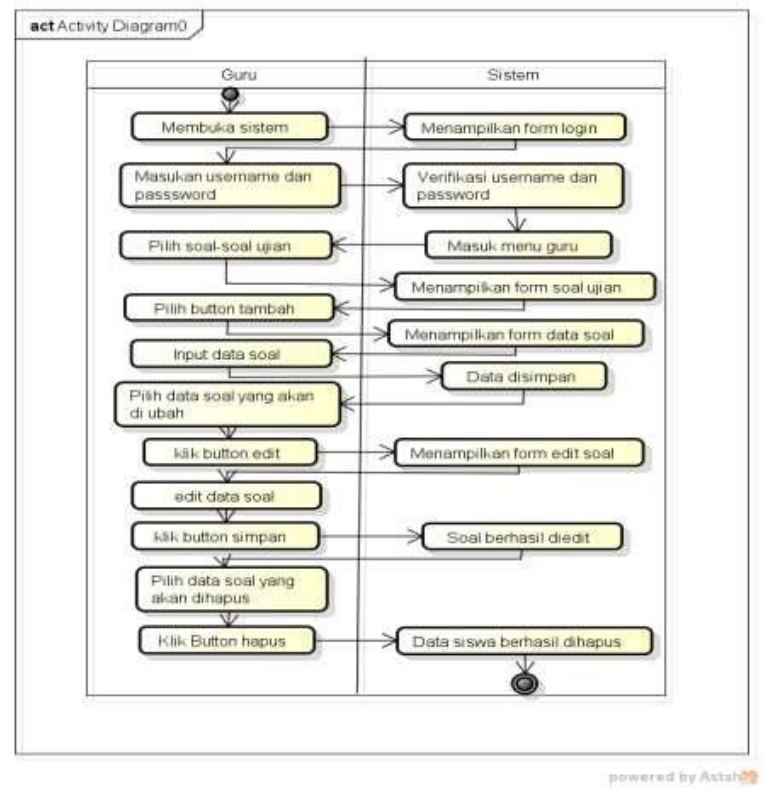

Gambar 3.4 Activity Diagram Manajemen Soal

2. Activity Diagram ujian

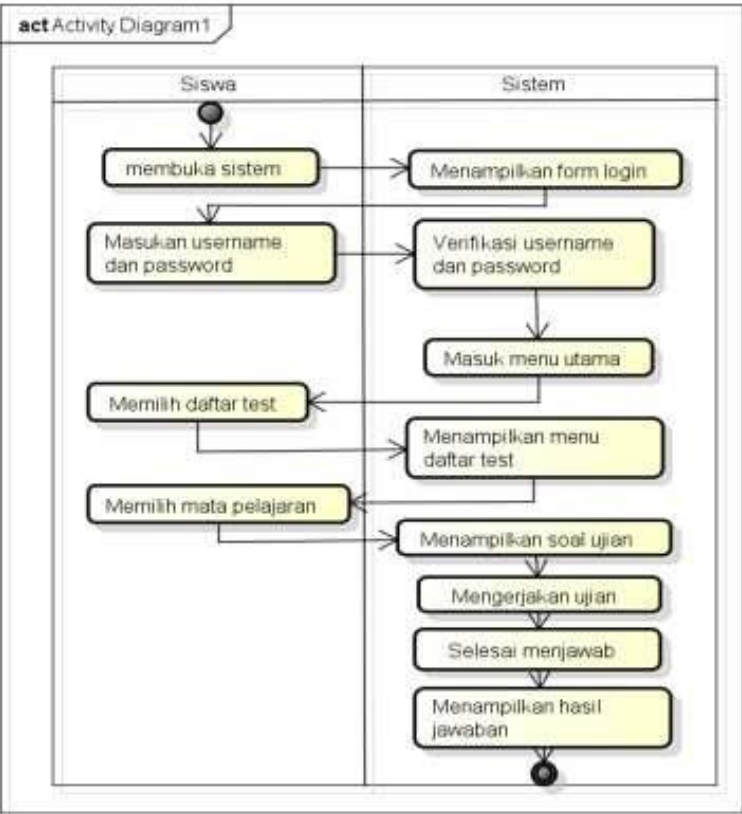

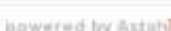

\section{Gambar 3.5 Activity Diagram Ujian}

\subsection{Class Diagram}

Berikut adalah rancangan class diagram yang dibuat untuk aplikasi pengacakan soal dengan menerapkan algoritma fisher-yates shuffle pada ujian sekolah SMKN1 Payung. Pada gambar dibawah, class diagram menampilkan ada sebanyak 7 kelas, dengan masing-masing kelas menjadi objek pada sistem ini.

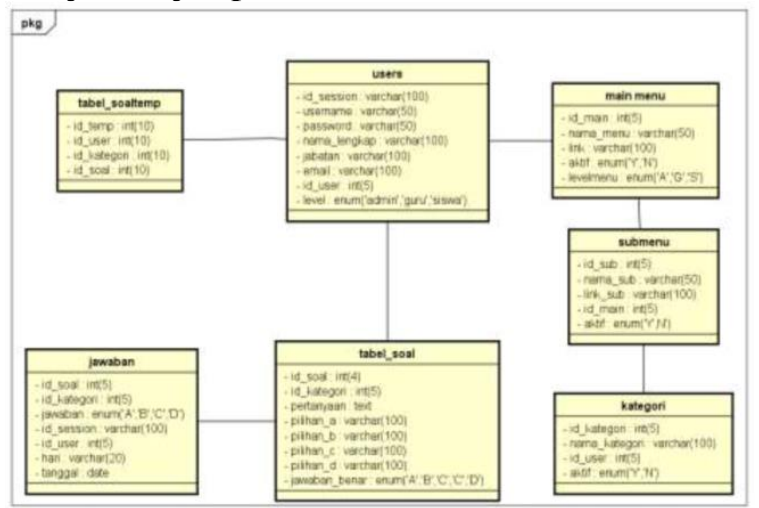

Gambar 3.6 Class Diagram

\subsection{Sequence Diagram}

Berikut Sequence Diagram yang melihat dari rancangan tampil web:

1. Sequence diagram manajemen soal 


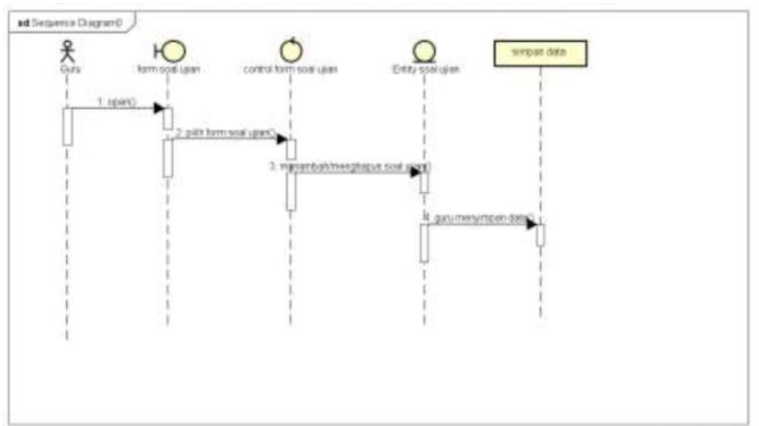

Gambar 3.7 Sequence diagram manajemen soal

2. Sequence diagram ujian sekolah

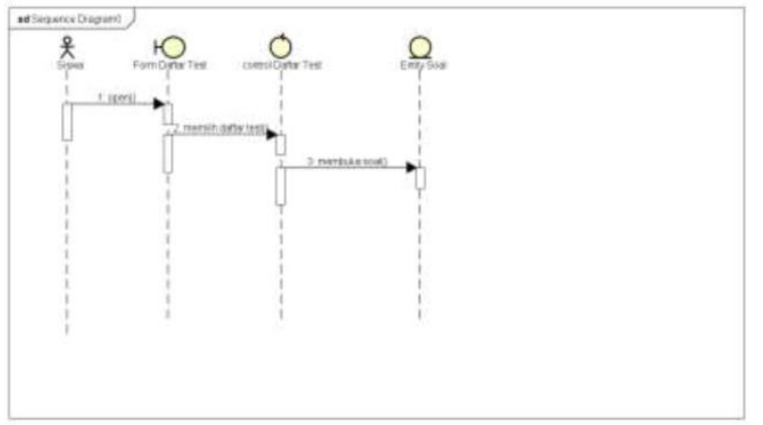

Gambar 3.8 Sequence diagram ujian sekolah

\subsection{Rancangan Layar}

Berikut adalah rancang layar pada aplikasi test berbasis komputer pada SMKN 1 Payung:

1. Rancangan layar login

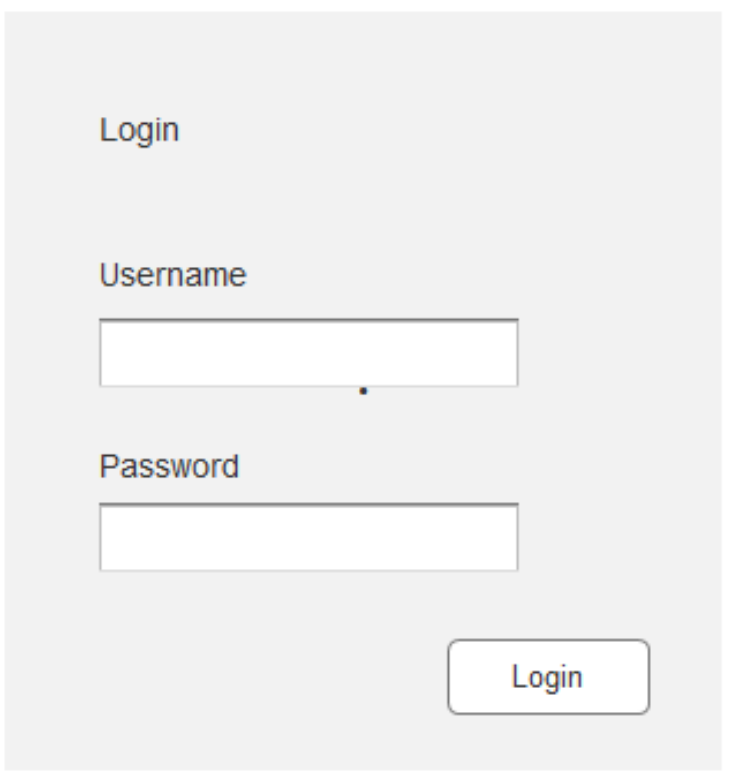

Gambar 3.9 Rancangan layar login

2. Rancangan layar manajemen soal

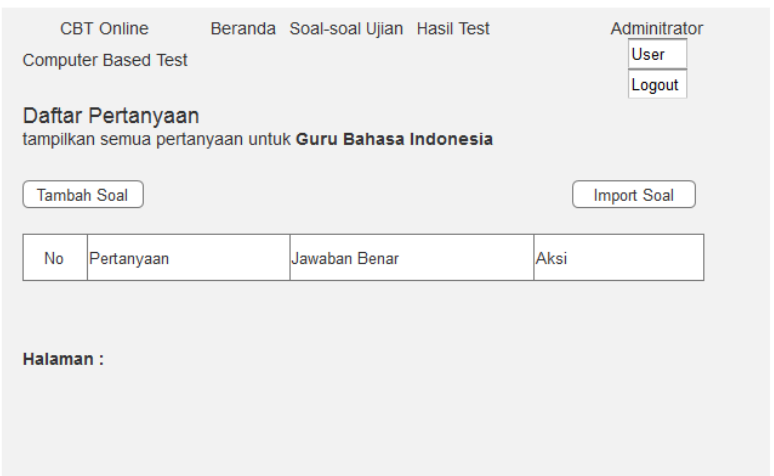

Gambar 3.10 Rancangan layar manajemen soal

3. Rancangan layar daftar ujian

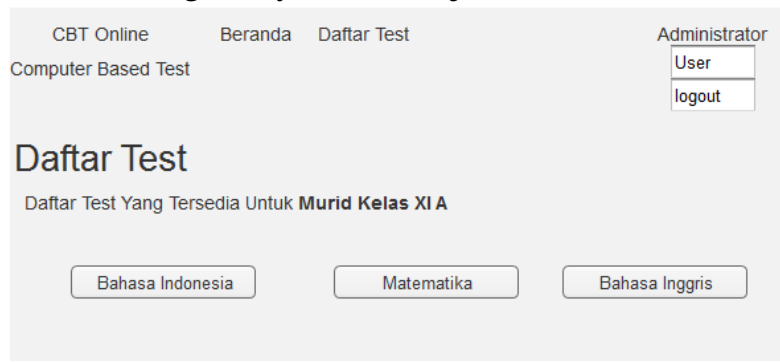

Gambar 3.11 Rancangan layar daftar ujian

4. Rancangan layar selesai mengerjakan soal ujian

\begin{tabular}{l|l|}
$\begin{array}{ll}\text { CBT Online } \\
\text { Computer Based Test }\end{array}$ & $\frac{A d m i n i s t r a t o r}{U \text { User }}$ \\
\hline Selamat Mengerjakan Yusuf Achsanul Azzam & Daftar Test \\
Jawab Pertanyaan Berikut Dengan Memilih Jawaban Dari Soal Bahasa Indonesia
\end{tabular}

Test Sudah Selesai Dilaksanakan, Terima Kasih

\begin{tabular}{|l|l|l|}
\hline No & Pertanyaan & Jawaban \\
\hline
\end{tabular}

Gambar 3.12 Rancangan layar selesai

\subsection{Implementasi}

Tahap implementasi adalah tahap dimana aplikasi diterapkan dan diuji, aplikasi yang dibangun menggunakan bahasa pemrograman PHP dan dengan menerapkan algoritma fisherfaces-yates shuffle untuk pengacakan soalnya diuji dan dipasang pada jaringan lokal SMKN 1 Payung.

1. Tampilan menu Login

Menu login digunakan untuk menjaga keamanan hak sistem. Terdapat pengguna dan kata sandi. 


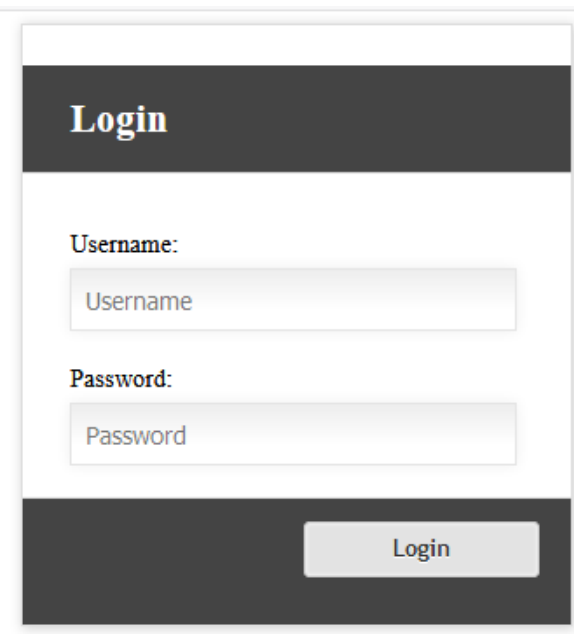

Gambar 3.13 Tampilan menu Login

2. Tampilan layar beranda

Pada tampilan layar beranda yaitu tampilan utama berguna untuk menampilkan informasi kontak.

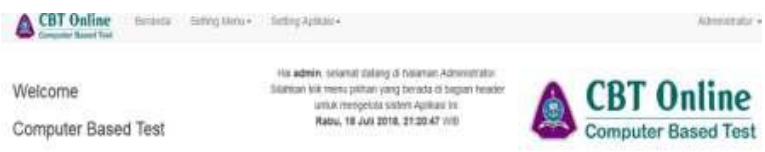

Gambar 3.14 Tampilan layar beranda

3. Tampilan layar kategori ujian

Pada tampilan layar kategori test menampilkan data pada tabel kategori test yang berisi mata pelajaran dan nama Guru, form kategori test berguna untuk manajemen data Guru. Admin dapat menghapus, mengedit dan tambah data Guru.

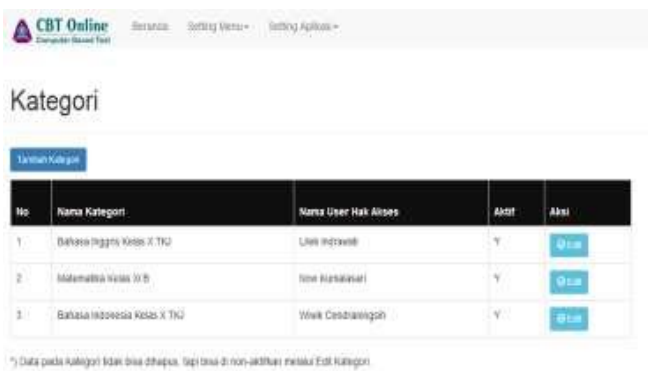

Gambar 3.15 Tampilan layar kategori ujian

4. Tampilan layar tambah user
Pada tampilan layar tambah user, menampilkan form pada tabel user, menu tambah untuk menambah atau menginput data yang ada pada user, data yang sudah dihapus bisa disimpan dan dibatal.

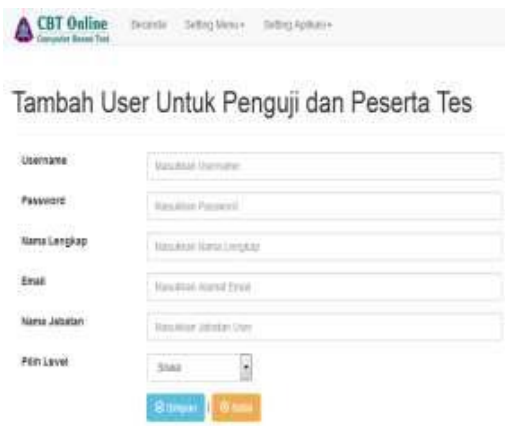

Gambar 3.16 Tampilan layar tambah user

5. Tampilan layar soal ujian

Pada tampilan layar Soal-soal Ujian meruapakan tampilan menu soal ujian yang digunakan guru untuk melihata soal ujian yang sudah di kerjakan oleh siswa.

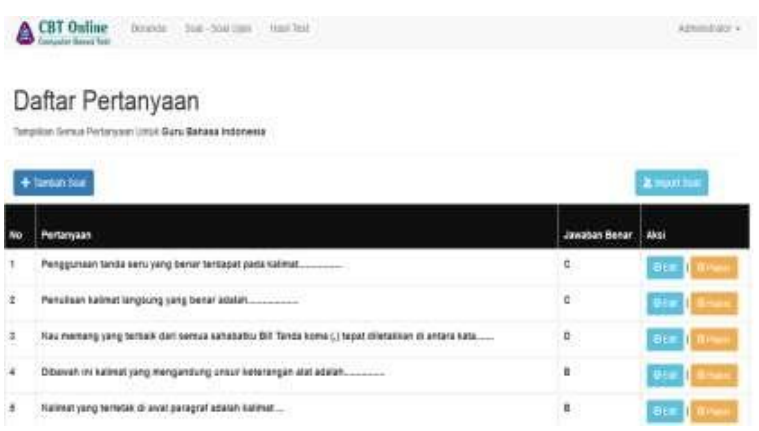

Gambar 3.17 Tampilan layar soal ujian

6. Tampilan layar tambah soal

Pada tampilan layar tambah soal, menampilkan form untuk menambah soal. Soal yang sudah di tambah bisa disimpan dan dibatal.

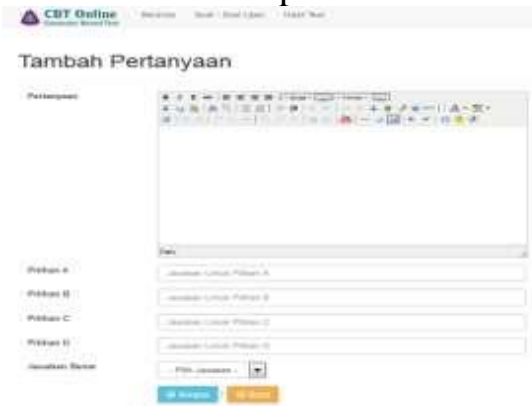

Gambar 3.18 Tampilan layar tambah soal

7. Tampilan layar daftar test 
Pada tampilan layar daftar test menampilkan soal-soal yang digunakan siswa untuk mengikuti ujian berbasis komputer.

ACBTOnine Bases caturat

\section{Datitar Test}

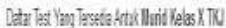

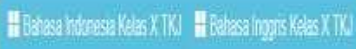

Gambar 3.19 Tampilan layar daftar test

8. Tampilan layar selesai mengerjakan Pada tampilan layar selesai mengerjakan soal ujian menampilkan form pertanyaan dan jawaban bahwa siswa telah selesai mengerjkan ujian test berbasis komputer.
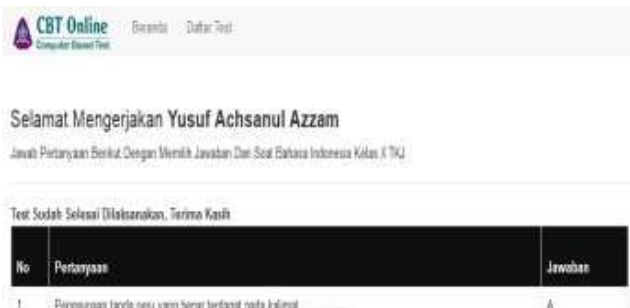

Gambar 3.20 Tampilan layar selesai mengerjakan

9. Tampilan layar logout

Pada tampilan layar logout hanya menampilkan bahwa anda sudah keluar dari halaman administrator anda.

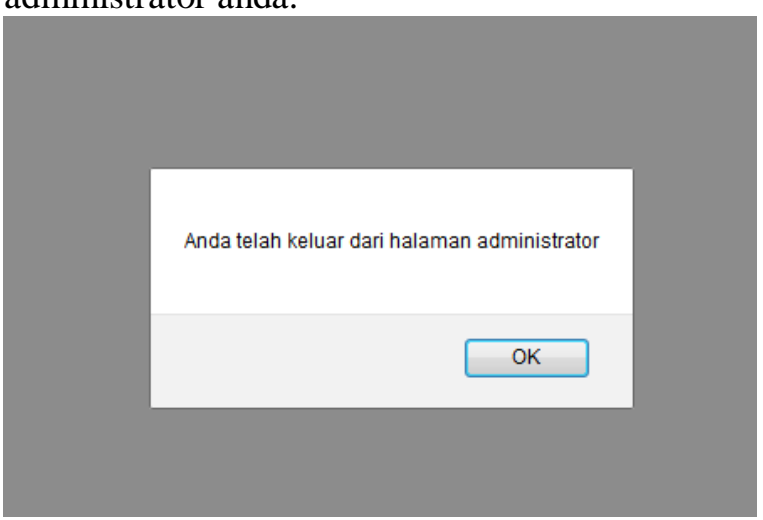

Gambar 3.21 Tampilan layar logout

\subsection{Pengujian}

Hasil pengujian yang dilakukan dengan menggunakan black box testing adalah sebagai berikut:

\begin{tabular}{|c|c|c|c|c|}
\hline No & Pengujian & Hasil yang diharapakan & Hasil Pengujian & Kesimpulan \\
\hline 1 & $\begin{array}{l}\text { Halaman } \\
\text { Awal } \\
\text { Sistem }\end{array}$ & $\begin{array}{l}\text { Dengan mulai localhost/yang } \\
\text { seharusnya sistem akan terbuka } \\
\text { dan menampilkan menu pada } \\
\text { sistem tersebut. }\end{array}$ & $\begin{array}{l}\text { Hasil dari pengujian } \\
\text { localhost/yang pada sistem } \\
\text { tersebut menampilkan menu } \\
\text { dalam web tersebut. }\end{array}$ & Sesuai \\
\hline 2 & $\begin{array}{l}\text { Menu } \\
\text { Setting }\end{array}$ & $\begin{array}{l}\text { Apabila menekan settting menu } \\
\text { dan lalu memilih menu utama, } \\
\text { maka akan muncul form menu } \\
\text { utama yang digunakan untuk } \\
\text { menambah data dan mengedit } \\
\text { data yang ada di admin. }\end{array}$ & $\begin{array}{l}\text { Dengan menekan menu utama } \\
\text { maka hasil yang diperoleh akan } \\
\text { berubah dari data yang telah di } \\
\text { edit atau di tambah. }\end{array}$ & Sesuai \\
\hline 3 & Sub Menu & $\begin{array}{l}\text { Apabila menekan sub menu maka } \\
\text { akan muncul form sub menu yang } \\
\text { digunakan untuk menambah atau } \\
\text { mengedit data yang ada di admin. }\end{array}$ & $\begin{array}{l}\text { Dengan menekan sub menu } \\
\text { maka hasil yang diperolah akan } \\
\text { berubah dari data yang telah } \\
\text { diedit atau ditambah. }\end{array}$ & Sesuai \\
\hline 4 & $\begin{array}{l}\text { Setting } \\
\text { Aplikasi }\end{array}$ & $\begin{array}{l}\text { Apabila menekan setting aplikasi } \\
\text { dan lalu memilih kategori test } \\
\text { hasil yang ditampilkan untuk } \\
\text { menambah dan mengedit kategori. }\end{array}$ & $\begin{array}{l}\text { Dengan menekan kategori test } \\
\text { hasil yang diperoleh perubahan } \\
\text { pada data kategori. }\end{array}$ & Sesuai \\
\hline 5 & $\begin{array}{l}\text { Reset } \\
\text { Aplikasi }\end{array}$ & $\begin{array}{l}\text { Apabila menekan reset aplikasi } \\
\text { maka akan menampilkan form } \\
\text { untuk mereset data yang ada pada } \\
\text { guru dan siswa. }\end{array}$ & $\begin{array}{l}\text { Dengan menekan reset aplikasi } \\
\text { data yang diperoleh masih tetap } \\
\text { seperti semula, karena data } \\
\text { tersebut tidak bisa direset, } \\
\text { tetapi hanya bisa di non } \\
\text { aktifkan melalui kategori test. }\end{array}$ & Sesuai \\
\hline 6 & $\begin{array}{l}\text { User } \\
\text { (Admin) }\end{array}$ & $\begin{array}{l}\text { Apabila menekan user maka } \\
\text { sistem akan muncul form user, } \\
\text { form tersebut bisa ditambah, } \\
\text { dihapus dan diedit. }\end{array}$ & $\begin{array}{l}\text { Dengan menekan tombol user } \\
\text { data yang kita tambah, hapus } \\
\text { dan edit akan berubah. }\end{array}$ & Sesuai \\
\hline
\end{tabular}

Gambar 3.22 Pengujian blackbox untuk admin

\begin{tabular}{|l|l|l|l|l|}
\hline No & Pengujian & Hasil yang diharapakan & Hasil Pengujian & Kesimpulan \\
\hline 1 & $\begin{array}{l}\text { Soal-soal } \\
\text { ujian }\end{array}$ & $\begin{array}{l}\text { Apabila menekan soal-soal ujian } \\
\text { maka sistem akan menampilkan } \\
\text { form soal ujian. Form soal } \\
\text { tersebut bisa ditambah atau } \\
\text { diimport }\end{array}$ & $\begin{array}{l}\text { Dengan menekan soal-soal } \\
\text { ujian maka di form yang } \\
\text { ditambah atau dimport maka } \\
\text { soal-soal ujian akan bertambah }\end{array}$ & Sesuai \\
\hline 2 & Hasil test & $\begin{array}{l}\text { Apabila menekan hasil test sistem } \\
\text { menampilkan hasil test yang } \\
\text { sudah dilaksanakan oleh siswa }\end{array}$ & $\begin{array}{l}\text { Dengan menekan hasil test } \\
\text { sistem menampilkan siswa } \\
\text { yang telah mengikutit test ujian } \\
\text { tersebut }\end{array}$ & Sesuai \\
\hline 3 & User guru & $\begin{array}{l}\text { Apabila menekan user maka akan } \\
\text { menampilkan form data guru yang } \\
\text { bisa diedit }\end{array}$ & $\begin{array}{l}\text { Dengan menekan user maka } \\
\text { data yang diedit bisa berubah }\end{array}$ & Sesuai \\
\hline
\end{tabular}

Gambar 3.23 Pengujian blackbox untuk guru

\begin{tabular}{|l|l|l|l|l|}
\hline No & Pengujian & Hasil yang diharapakan & Hasil Pengujian & Kesimpulan \\
\hline 1 & Daftar test & $\begin{array}{l}\text { Dengan menekan daftar test maka } \\
\text { sistem akan memunculkan soal- } \\
\text { soal test untuk siswa }\end{array}$ & Siswa telah melaksakan ujian & Sesuai \\
\hline 3 & User siswa & $\begin{array}{l}\text { Dengan menckan user siswa bisa } \\
\text { mengedit data siswa }\end{array}$ & $\begin{array}{l}\text { Dengan menckan tombol user, } \\
\text { data yang telah diedit bisa } \\
\text { berubah }\end{array}$ & Sesuai \\
\hline
\end{tabular}

Gambar 3.24 Pengujian blackbox untuk siswa

\section{SIMPULAN DAN SARAN}

4.1 Kesimpulan

Dari hasil penelitian yang dilakukan, maka didapatkan kesimpulan sebagai berikut:

1. Aplikasi Test Berbasis Komputer di SMKN 1 Payung sudah berhasil dibuat oleh penulis yang berisi mengenai pengacakan soal, 
sehingga dengan adanya algoritma fisheryates shuffle ini dapat membantu meminimalisir adanya kecurangan menyontek yang biasa dilakukan oleh siswa.

2. Hasil pengujian blackbox yang dilakukan membuktikan bahwa fungsionalitas aplikasi yang dibuat sudah sesuai, dan dapat diterapkan di SMKN 1 Payung untuk memenuhi kebutuhan test berbasis komputer ujian sekolah.

\subsection{Saran}

Adapun saran-saran dari hasil penelitian yang dilakukan, adalah sebagai berikut:

1. Diharapkan adanya pengembangan dari aplikasi ini untuk kedepannya karena masih terdapat kekurangan seperti melaksanakan ujian test berbasis komputer.

2. Diharapkan aplikasi yang tersedia bisa lebih ditingkatkan lagi.

3. Diharapkan pada penelitian berikutnya dapat diterapkan dengan menggunakan algoritmaalgoritma sejenis lainnya seperti algoritma linear congruent method (LCM). Agar aplikasi ini mempunyai fungsi yang lebih banyak lagi dan menjadi lebih baik

\section{UCAPAN TERIMA KASIH}

Penulis menyampaikan ucapan terima kasih kepada:

1. Bapak Adam Malik, S.Pd selaku kepala sekolah SMKN 1 Payung, beserta staf guru dan tata usaha

2. Ibu Asmi yang telah berbaik hati saya repotkan dalam pengambilan data-data yang diperlukan selama riset.

\section{REFERENSI}

[1] D. O'Connor, A Historical Note on Shuffle Algorithms. Dublin, University College Dublin: UCD Press, 2017.

[2] Ekojono, D. A. Irawati, L. Affandi, A. N. Rahmanto, Penerapan Algoritma FisherYates pada Pengacakan Soal Game Aritmatika, in Prosiding SENTIA, 2017, vol. 9, pp. 101-106. http://sentia.polinema.ac.id/index.php/SENT IA2017/article/download/237/225

[3] A. O. Ade-Ibijola, A Simulated Enhancement of Fisher-Yates Algorithm for Shuffling in Virtual Card Games using Domain-Specific Data Structures, Int. J.
Comput. Appl., vol. 54, no. 11, pp. 24-28, 2012. DOI: $10.5120 / 8612-2469$

[4] A. A. In'Amin, Pembuatan Game Edukasi Tajwid Sebagai Sarana Pembelajaran di Taman Pendidikan Qur-an Hidayatul Amin, Jurnal Simki-Techsain Vol. 02 No. 03, 2018.

[5] R. Nugraha, E. Exridores, H. Sopryandi, Penerapan Algoritma Fisher-Yates Pada Aplikasi The Lost Insect Untuk Pengenalan Jenis Serangga Berbasis Unity 3D, STMIK GI MDP Palembang, 2018.

http://simki.unpkediri.ac.id/mahasiswa/file_ artikel/2018/4fe303394fbe406d6a0ede74be6 acc73.pdf

[6] I, Haditama, C. Slamet, D. F. Rahman, Implementasi Algoritma FisherYates dan Fuzzy Tsukamoto Dalam Game Kuis Tebak Nada Sunda Berbasis Android, Jurnal JOIN, 1(1), pp. 51-58, 2016.

http://join.if.uinsgd.ac.id/index.php/join/arti cle/view/v1i110

[7] W. J. Satzinger, B. R. Jackson, \& D. S. Burd, System Analysis and Design in a Changing World, Boston: Massachucet, 2010.

[8] A. Hariyanto, Membuat Aplikasi Computer Based Test dengan PHP MySQL \& Bootstrap. Yogyakarta: Lokomedia, 2017.

[9] R. M. Stair, and G. W. Reynolds, Fundamentals of Information System, Stamford: Cengage Learning, 2010. 